\title{
CHEBYSHEV AND GRÜSS TYPE INEQUALITIES INVOLVING TWO LINEAR FUNCTIONALS AND APPLICATIONS
}

\author{
LudMila NikOlova AND SANJA VAROŠANEC
}

\begin{abstract}
In the present paper we prove the Chebyshev inequality involving two isotonic linear functionals. Namely, if $A$ and $B$ are isotonic linear functionals, then $A(p f g) B(q)+A(p) B(q f g)$ $\geqslant A(p f) B(q g)+A(p g) B(q f)$, where $p, q$ are non-negative weights and $f, g$ are similarly ordered functions such that the above-mentioned terms are well-defined. If functionals are equal, i.e. $A=B$ and if $p=q$, then the above inequality becomes the Chebyshev inequality involving one isotonic linear functional: $A(p) A(p f g) \geqslant A(p f) A(p g)$ in which we recognize a generalization of the well-known classical integral and discrete Chebyshev inequalites as special cases.

We derive various properties of functionals related to the difference of the right-hand and the left-hand sides of the above-mentioned inequalities. The most remarkable results are the Grüss type inequalities for two functionals. Inequalities involving some fractional integral operators are also given.
\end{abstract}

Mathematics subject classification (2010): 26D20, 26A33.

Keywords and phrases: The Chebyshev inequality, the Grüss inequality, isotonic linear functional, fractional integral operator.

\section{REFERENCES}

[1] D. Andrica, C. BADEA, Grüss inequality for positive linear functionals, Periodica Mathematica Hungarica, 19 (2) (1988), 155-167.

[2] D. AndricA, I. RAŞA, Nets in $M_{+}^{1}(X)$ and mean-value theorems, Seminar on Math. Analysis (Babeş-Bolyai University, Cluj-Napoca), Preprint 7 (1985), 7-12.

[3] D. Baleanu, S. D. Purohit, Praveen Agarwal, On fractional integral inequalities involving hypergeometric operators, Chinese Journal of Mathematics, Volume 2014 (2014), Article ID 609476.

[4] S. Belarbi, Z. Dahmani, On some new fractional integral inequalities, Journal JIPAM, 19 (3) (2009), Art. 86.

[5] V. L. Chinchane, D. B. Pachpatte, On some integral inequalities using Hadamard fractional integral, Malaya Journal of Matematik, 1 (1) (2012), 62-66.

[6] V. L. Chinchane, D. B. PAChPATte, A note on some fractional integral inequalities via Hadamard integral, Journal of Fractional Calculus and Applications, 4 (1) (2013), 125-129.

[7] V. L. Chinchane, D. B. Pachpatte, On some Grüss-type fractional inequalities using Saigo fractional integral operator, Journal of Mathematics, Volume 2014, Article ID 527910.

[8] V. L. Chinchane, D. B. Pachpatte, On some new Grüss-type inequality using Hadamard fractional integral operator, Journal of Fractional Calculus and Applications, 5 (3S) (12) (2014), 1-10.

[9] L. CURIEL, L. GALUÉ, A generalization of the integral operators involving the Gauss hypergeometric function, Revista Técnica de la Facultad de Ingenieria Universidad del Zulia, 19 (1) (1996), 17-22.

[10] Z. Dahmani, The Riemann-Liouville operator to generate some new inequalities, International Journal of Nonlinear Science, 12 (4) (2011), 452-455.

[11] Z. Dahmani, L. TABharit, S. TAF, New generalisations of Grüss inequality using RiemannLiouville fractional integrals, Bulletin of Mathematical Analysis and Applications, 2 (3) (2010) 93-99. 
[12] Z. Dahmani, Q. Mechouar, S. Brahami, Certain inequalities related to the Chebyshev functional involving Riemann-Liouville operator, Bulletin of Mathematical Analysis and Applications, 3 (4) (2011), 38-44.

[13] S. S. DRAGOMIR, A Grüss type inequality for isotonic linear functionals and applications, Research Report Collection, 5 (2002), Supp. art. 12.

[14] S. L. KAlla, A. RaO, On Grüss type inequality for a hypergeometric fractional integral, Le Matematiche, Vol. LXVI (2011), Fasc. I, 57-64.

[15] V. Kiryakova, Generalized Fractional Calculus and Applications, Pitman Research Notes in Mathematics Series, Vol. 301, Longman Scientific and Technical, Harlow, 1994.

[16] N. Minculete, L. Ciurdariu, A generalized form of Griuss type inequality and other integral inequalties, Journal of Inequalities and Applications, 2014, 2014:119.

[17] L. Nikolova, S. VARoš ANEC, Properties of mappings generated with inequalities for isotonic linear functionals, Proceedings of Constructive Theory of Functions 2013, Sozopol, Bulgaria, Prof. Marin Drinov Academic Publishing House, Sofia, 2014, pp. 199-215.

[18] J. E. PeČArić, F. Proschan And Y. L. Tong, Convex functions, partial orderings, and statistical applications, Academic Press Inc., 1992.

[19] J. PEČARIĆ, B. TEPEŠ, On a Grüss type inequality for isotonic linear functionals I, Nonlinear Studies, 12 (2) (2005), 119-125.

[20] S. D. Purohit And R. K. Raina, Chebyshev type inequalities for the Saigo fractional integrals and their q-analogues, Journal of Mathematical Inequalities 7 (2) (2013), 239-249.

[21] A. Secer, S. D. Purohit, K. A. Selvakumaran, M. Bayram, A generalized q-Grüss inequality involving the Riemann-Liouville fractional q-integrals, Journal of Applied Mathematics, Volume 2014, Article ID 914320.

[22] W. SudsutAd, S. K. NTOUYAs, AND J. TARIBOOn, Fractional integral inequalities via Hadamard's fractional integral, Abstract and Applied Analysis, Volume 2014 (2014), Article ID 563096.

[23] J. Tariboon, S. K. Ntouyas, W. Sudsutad, Some new Riemann-Liouville fractional integral inequalities, International Journal Of Mathematics and Mathematics Sciences, Volumen 2014, Article ID 869434.

[24] G. WAng, P. Agarwal, M. Chand, Certain Grüss type inequalites involving the generalized fractional integral operator, Journal of Inequalities and Applications, 2014, 2014:147. 